\title{
FDS+Evac models and cryogenic and oxygen deficiency emergency management for underground facilities in Gran Sasso National Laboratories
}

\author{
M. Tobia ${ }^{1,2}$, R. Tartaglia ${ }^{1}$, R. Perruzza ${ }^{1} \&$ F. Nusca ${ }^{2}$ \\ ${ }^{1}$ PPS Department, National Institute of Nuclear Physics, \\ Gran Sasso National Laboratory, Italy \\ ${ }^{2}$ DIIIE, Department of Industrial and Information Engineering \\ and Economics, University of L'Aquila, Italy
}

\begin{abstract}
The aim of this work is to refine the emergency and evacuation management by the application of FDS+Evac (by NIST and VTT) models within the Gran Sasso National Laboratories (LNGS); one of the structures owned and managed by the Italian National Institute for Nuclear Physics (INFN). The application of these models to a peculiar site, such as the LNGS one, has the fundamental role to evaluate the correct definition of the emergency procedures proposed and adopted inside the plant. Thus ensuring, by an agent-based dynamic simulation, a preliminary evaluation of the behaviour of users and emergency teams in case of emergency and, specifically, an assessment of the time of intervention and full evacuation from the site. The analysis has been applied to a new experimental installation in one of the main experimental halls of the LNGS. The object of the study has been the simulation of evacuation after a direct nitrogen release in the service building of the Xenon1T experiment, located in Hall B of the underground laboratories. The implemented models have the great potential to take into account not only the characteristics of the surrounding environment, but also the psychological and human aspects induced in people involved in an emergency. The study aims to provide a first step evaluation of the accuracy of the Internal Emergency Plan (PEI) procedures adopted in the LNGS, highlighting the pros, cons, critical aspects, future progresses and the possibility of
\end{abstract}


widening the analysis to the entire site in view of continuous improvement in the matter of safety and emergency management.

Keywords: safety, emergency management, FDS+Evac, confined space, ODH, asphyxia, underground laboratory.

\section{Gran Sasso National Laboratories: INFN}

The Gran Sasso National Laboratories (LNGS) are one of the experimental research centres belonging to the Italian National Institute of Nuclear Physics (INFN). The LNGS facility is made up of two main areas:

- An external operations centre in Assergi, L'Aquila;

- Underground laboratories.

Both of the areas are located in the heart of Gran Sasso and Monti della Laga National Park. The underground laboratories, housing about 20 experiments, are located under a rock layer of about 1,400 $\mathrm{m}$ of thickness, acting as a shield against cosmic radiation. The underground cavity is just in the middle of the Gran Sasso highway tunnels (a double-tunnel 10,500 m long gallery). Moreover, LNGS are surrounded by a huge water reservoir. The research areas in which the laboratories operate or plan to operate are:

- the study of rare nuclear phenomena;

- the study of the most penetrating components of cosmic rays;

- neutrino physics;

- dark matter.

LNGS consist of three experimental halls of about $100 \times 20 \times 20 \mathrm{~m}^{3}$ each: Hall A, Hall B, Hall C. The connection among the halls is achieved by other smaller galleries: car tunnel, truck tunnel, connecting tunnels.
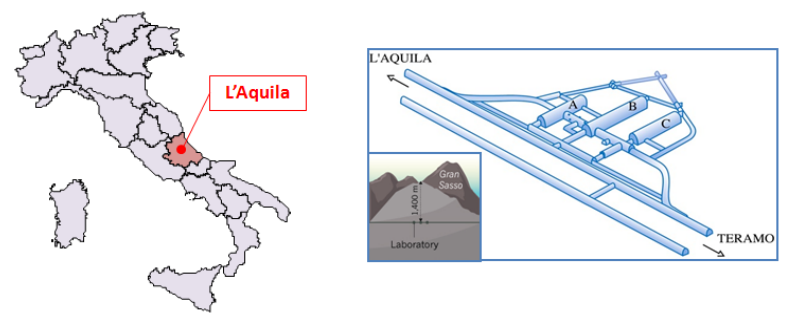

Figure 1: Gran Sasso National Laboratories, underground laboratories.

From the "safety point of view", besides health and safety regulations in the work place, LNGS are subjected to the European Directive Seveso III (2003/105/CE): they are classified as major accident hazard plant because of Experiments using and storing big amounts of substances classified as dangerous for the environment [1]. In compliance with Seveso, LNGS have adopted a Safety Management System (SGS) implemented through 16 procedures and operating instructions. Furthermore, LNGS have a specific Internal Emergency Plan (PEI) and a General Emergency Plan (PEE - including the PEI and the emergency aspects connected with the complex surrounding environment). Moreover, before 
starting any activity or new project/experiment, LNGS and Experimental Collaborations must realize a Safety Risk Analysis in order to evaluate the likelihood of occurrence of possible events and to guarantee the highest safety standards in a complex system such as the one in which LNGS are involved.

\section{Xenon1T experiment}

Several extensions of the standard model of particle physics lead to the Weakly Interacting Massive Particles (WIMPs) as candidates for the demonstration of astrophysical dark matter. Xenon1T is an experimental project for the direct search for dark matter designed to look for WIMPs through a detector in the laboratory with unprecedented sensitivity.

The experiment is in phase of completion inside the Underground Laboratories in Hall B, a 100x20x20 $\mathrm{m}^{3}$ area (fig. 2).

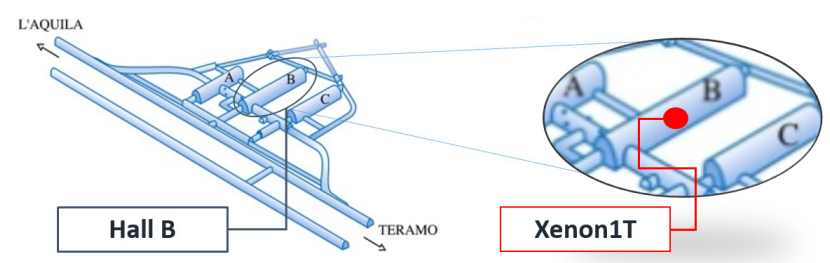

Figure 2: The Hall B and the Xenon1T location.

The infrastructure of Xenon1T is composed of two main elements: the Water Tank providing the needed shielding for Xenon1T's detector and a Service Building containing all the systems and equipment for the experiment running (i.e. the cooling and purification systems; DAQ and electronic controls, the storage tank of xenon gas).

Table 1: Xenon1T's infrastructure and characterisation.

\begin{tabular}{|l|c|c|c|}
\hline \multicolumn{2}{|c|}{ Water tank } & \multicolumn{2}{c|}{ Service building } \\
\hline Description & $\begin{array}{c}\text { Vertical cylinder with conic } \\
\text { roof (stainless steel AISI304) }\end{array}$ & Description & 3-floor steel structure \\
\hline Volume & $\sim 700 \mathrm{~m}^{3}$ & Volume & $\sim 600 \mathrm{~m}^{3}$ \\
\hline Weight & $\sim 33,500 \mathrm{~kg}$ & Width & $7,000 \mathrm{~mm}$ \\
\hline Diameter & $9,600 \mathrm{~mm}$ & Length & $8,000 \mathrm{~mm}$ \\
\hline Height & $11,600 \mathrm{~mm}$ & Height & $11,000 \mathrm{~mm}$ \\
\hline
\end{tabular}

The Xenon1T's cryogenic infrastructure consists of six interconnected systems:

- Xenon Refrigeration System: used to cool the Xenon1T's detector, liquefy the gas Xenon and keep it at an operating temperature of about $180 \mathrm{~K}$;

- Xenon Storage and Recovery System (ReStox): a double wall vacuum insulation spherical vessel designed to withstand an absolute pressure of 65 bar, allowing conservation of Xenon in the gas phase;

- Xenon Purification System; 
- Column for the Removal of Radon (charcoal);

- Column for the Removal of Krypton;

- Monitoring and Control System.

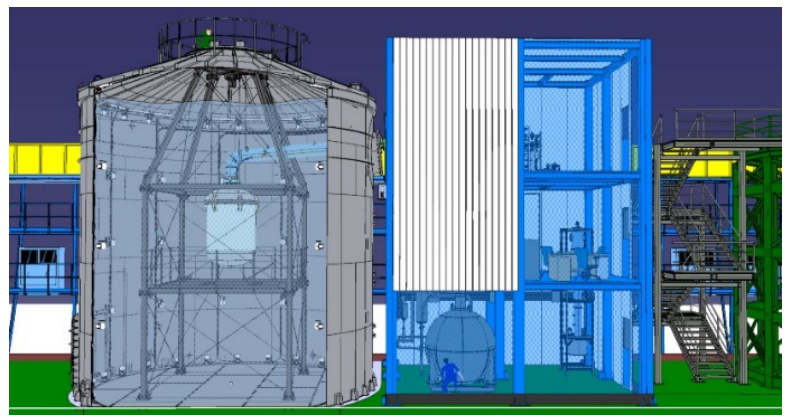

Figure 3: 3D representation of the Xenon1T Experiment in Hall B of the LNGS.

\section{Cryogenic and oxygen deficiency hazard (ODH)}

The Xenon1T Experiment uses cryogenic fluids for both the scientific (detection of WIMPs) and operating purposes (i.e. refrigeration). In particular, the fluids processed in the Xenon1T apparatus are gaseous and liquid Xenon and nitrogen. The use, storage and processing of cryogenic fluids in a close and confined space, such as the one of the Underground Laboratories, imposes a punctual evaluation of the associated risks and the definition and implementation of preventive and protective measures to guarantee high safety standard for people and equipment.

The elements responsible of the cryogenic fluids' hazards, basically, are their temperature and typology. The hazards of physiological derivation intervene because of the very low temperatures of cryogenic fluids and, in particular, have effects affecting the human beings. Among the main hazards of direct type there are:

- damage to human tissue - hypothermia: very cold temperatures are an obvious danger if the fluid may come into contact with human tissue. Some contacts may lead to an almost instantaneous freezing, and the resulting damage for the skin can be compared to a thermal burn. This damage is called "frostbite" or "cryogenic burn". Although it seems obvious the importance of preventing any contact with both the cryogenic liquid and cold gas, an equal important precaution is to preclude the possibility of contact - even instantaneous - with any cold metal which is at cryogenic temperatures (below $-100^{\circ} \mathrm{C}$ ). Moreover, body heat is maintained by metabolism, by the action of muscles and breathing. If the body is not able to generate heat in an amount equal to the one lost, body temperature will decrease continuously, with the result of hypothermia. If the body temperature falls below $35^{\circ} \mathrm{C}$, a deterioration of the organic functions at nervous, cardiac and respiratory level may appear. At temperatures below $28^{\circ} \mathrm{C}$, ventricular fibrillation appears. In many cases, a person in an environment where there may be hypothermia can hardly be able to escape. 
- hypo-oxygenation: the cryogenic liquid evaporates if it is heated to room temperature. The presence of a relatively small amount of cryogenic liquid can dilute the breathable atmosphere (normally $21 \%$ of oxygen concentration in air) in a place near the feed point of the liquid. The situation is made more critical by releases occurring in very small confined spaces. The consequences of an oxygen deficiency appear to be different in relation to the diverse response between a person and another. In any way, it is possible to draw up a list of symptoms and effects generally found in subjects exposed to a given percentage of oxygen concentration in the air (Table 2).

Table 2: $\quad$ Symptoms and effects of oxygen deficiency [2].

\begin{tabular}{|c|l|}
\hline \% of oxygen in volume & \multicolumn{1}{|c|}{ Symptoms and effects } \\
\hline $15-19$ & $\begin{array}{l}\text { Possible abnormal coordination; could lead to early symptoms in people } \\
\text { with heart, respiratory or circulatory problems. }\end{array}$ \\
\hline $12-15$ & $\begin{array}{l}\text { Wheeze; accelerated pulse; judgment, coordination and perception } \\
\text { altered. }\end{array}$ \\
\hline $10-12$ & $\begin{array}{l}\text { Breathing difficulty and increased rhythm; blue lips; poor coordination } \\
\text { and judgment. }\end{array}$ \\
\hline $8-10$ & $\begin{array}{l}\text { Nausea; vomiting; livid face; mental confusion; fainting; loss of } \\
\text { consciousness. }\end{array}$ \\
\hline $6-8$ & $\begin{array}{l}4-5 \text { minutes of exposure: recovery only after first aid; 6 minutes of } \\
\text { exposure: fatal in 25-50\% of cases; 8 minutes of exposure: fatal in 50- } \\
100 \% \text { of cases. }\end{array}$ \\
\hline $4-6$ & Coma in 40 seconds; convulsions; respiratory arrest; death. \\
\hline
\end{tabular}

An oxygen-depleted atmosphere is defined as an "oxygen deficiency atmosphere" when the $\mathrm{O}_{2}$ concentration in the environment is less than $19.5 \%$. The hypo-oxygenation is a very critical hazard because of its inherent characteristics: it occurs instantly and without warning. The insidious danger is related to the occurrence of anoxia (the decrease or total lack of oxygen at cellular level) characterized by being unnoticed by the body. In these conditions, a person hardly notices the danger and even more hardly moves away from the dangerous area. In fact, cryogenic fluids have the characteristic to be odourless, colourless and tasteless.

Considering the accidental scenario object of this study, it will be easy to understand the criticality of a cryogenic release in the particular conditions in which it occurs. The scenario, in fact, evolves in a building, inside a confined underground environment, with the presence of staff.

\section{Human behaviour during evacuation}

The evacuation from a building interested by an emergency is a complex process. The presence of a fire or, in this study, of an ODH is a very critical aspect. Moreover, if we consider the evolvement of the emergency in a multi-ethnic and international environment such as the LNGS, the process is clearly more complex. This process starts when people become conscious of the emergency putting in place a series of mental processes and activities before and after the actions that lead them to a safe place. Thus, is possible to define the reference parameters for the evacuation [3]: 
- RSET (Required Safety Egress Time): is the time necessary for a person to reach a safe place, far from the accidental area. In order to define it, is essential to know the personal characteristics of reaction to an emergency;

- ASET (Available Safety Egress Time): is the maximum allowed time by the event (i.e. a fire) guaranteeing the surviving conditions. In order to define it, is essential to know the event's boundary conditions.

A safe and successful evacuation is necessary associated to the following relation comparing the required and available egress times:

$$
\text { RSET < ASET }
$$

It is therefore evident that the difficulty resides in the assessment of the human behaviour. RSET definition is strictly linked to the interaction between people and the environment around them. Related to the people's characteristics and the behaviour in an environment, it is possible to divide the type of response in three groups [3]:

- interaction between physical ability of people and environment;

- interaction between cognitive ability of people and environment;

- interaction between physical and cognitive ability of people and environment. Focusing on the characteristics of "occupants" (people inside a building) some of the key aspects are the knowledge of the place; the familiarity with emergency procedures; the reaction ability; the reaction speed.

All these elements determine the knowledge of the reaction, interpretation and validation process of clues. Detection systems, alarm systems, direct perception of the products of combustion (i.e. during a fire), communication by other people, stop of services and facilities are some of the possible clues available and that are not essential for the starting of the exodus. The clues validation's process (Table 3 ) is mainly composed of three phases: reception (feeling physically); recognition (recognizing the clue for what it is); interpretation (giving the real meaning to the clue). These validations vary according to the physical and psychological characteristics of the person perceiving the clues.

Table 3: Clues validation's process.

\begin{tabular}{|c|c|c|c|c|}
\hline $\begin{array}{c}\text { Starting or development } \\
\text { of the emergency and of } \\
\text { the clue }\end{array}$ & \multicolumn{4}{|c|}{ Clues validation's process } \\
\hline \multirow{2}{*}{$\begin{array}{c}\text { Clues' } \\
\text { reception }\end{array}$} & $\begin{array}{c}\text { Clues' } \\
\text { recognizing }\end{array}$ & $\begin{array}{c}\text { Clues' } \\
\text { interpretation } \\
\text { Decision's period }\end{array}$ & $\begin{array}{c}\text { Reception, } \\
\text { recognizing, } \\
\text { interpretation... }\end{array}$ \\
\cline { 2 - 5 } & \multicolumn{3}{|c|}{ Pre-movement period } & $\begin{array}{c}\text { Decision during } \\
\text { the movement }\end{array}$ \\
\cline { 2 - 4 } & \multicolumn{3}{|c|}{$\begin{array}{c}\text { Movement until } \\
\text { the safe place }\end{array}$} \\
\hline
\end{tabular}

The decision process goes through other evaluations made by the person after the perceived clues. We can distinguish:

- finding further information;

- finding other people;

- trying to warn other people; 
- trying to "solve the problem";

- starting the evacuation;

- continuing the own activity.

\section{FDS+Evac modelling}

The dimensioning and design of escaping routes follows the so-called "traditional model": a prescriptive approach based on the laws and rules' respect. Aiming at overcoming this traditional model, following the so-called "performance-based approach" suggested and foreseen by law, a flux/fluid dynamic model has been adopted to solve the problems and peculiar elements of the case study. The basic hypothesis is that all the people present are contemporary warned and start the exodus without delay and not changing their physical conditions during the exodus. The "movement's time" is determined by the distance to cover and by the speed and is divided in:

- time to free the building;

- time to free the floor;

- time to free the stairs;

- time needed by the person covering the longest path.

Using the method proposed by Nelson and Mowrer, the evacuation time can be defined as the following relation:

$$
t=t_{1}+t_{2}+t_{3}
$$

where $t_{1}$ is the time needed for the first person to reach the escaping route's control element; $t_{2}$ is the time needed for the group to overcome the escaping route's control element; $t_{3}$ is the time needed for the last person to leave the control element and to reach the safe place (the control element is the element of the escape route which obliges the group to form the longest queue).

In order to obtain reliable results and simulations, the real scenario has been modelled using FDS+Evac: the evacuation module of the Fire Dynamic Simulator (FDS). FDS+Evac allows also simulating only the human egress process without any fire effects. This model treats each evacuee as a separate entity, named "agent", which has its own personal properties and escaping strategies. The movement of the agents is simulated using two-dimensional planes representing the floors of buildings. The basic algorithm behind the egress movement solves an equation of motion for each agent in a continuous 2D space and time, i.e., FDS+Evac is doing some kind of an artificial molecular dynamics for the agents. The forces acting on the agents consist of both physical forces, such as contact forces and psychological forces exerted by the environment and other agents [46]. Finally, the post-processor Smokeview (SMV is a separate visualization program that is used to display the results of an FDS simulation) has been used to display the results of the simulation and to have a clear view of the scenario's evolution. 


\section{Emergency scenario}

The emergency scenario taken into account occurs in the Service Building of the Xenon1T Experiment. As shown before, this is a three-floor steel structure hosting the following parts:

- ground floor: pumps and compressors room, hosting the Xenon Storage and Recovery System (ReStox) and the base of the distillation column;

- first floor: hosting electronics and the control room;

- second floor: hosting cryogenic equipment.

The emergency evolves in Hall B of the Underground Laboratories (fig. 4). The entire experimental hall, in particular $44 \mathrm{~m}$ from the Service Building to the "South side filter" (considered as an "assembly point"), has been modelled.

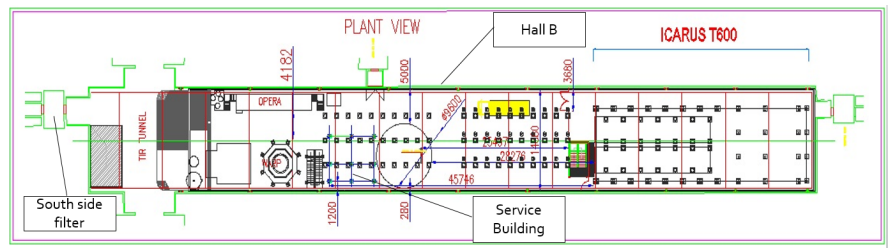

Figure 4: Plant view of Hall B.

\subsection{Top event: direct nitrogen release in Hall B}

The Safety Risk Analysis (SRA) performed for the experimental apparatus with HazOp, FMEA and FTA methods, highlighted the top event "direct nitrogen release in Hall B". As defined in the SGS of the LNGS, the SRA are elaborated by the Experimental Collaboration, examined and approved by the LNGS. In the Xenon1T case, the event reported is one of the top events highlighted in the SRA. LNGS, and in particular the Prevention and Protection Service (SPP) of the labs, have chosen this event as the one to be deepened according with the high risk of such release in a closed and confined space with people present. The Safety Risk Analysis resulted into a possible release due to hole or leak from valves, pipes or systems devoted to the operating of Xenon1T apparatus.

Considering the event, the following step has been the calculation of the time needed to reach a percentage of oxygen in the air of $18 \%$ (Table 2 ). The relation used, based on an $\mathrm{O}_{2}$ balance for the confined volume, is the following one [7]:

$$
C(t)=0,21 e^{-\frac{R}{V} t}
$$

where $\mathrm{C}(\mathrm{t})$ is the oxygen concentration $(\mathrm{C}(\mathrm{t})$ is 0.21 when $\mathrm{t}$ is 0$)$; $\mathrm{R}$ is the rate of release of nitrogen in the building (set at $0.1 \mathrm{~m}^{3} / \mathrm{s}$ ); $\mathrm{V}$ is the volume of the building (set at $280 \mathrm{~m}^{3}$ considering the internal encumbrances); $\mathrm{t}$ is the time in seconds. Obtaining $\mathrm{t}$ from eqn (3):

$$
t=\ln \left(\frac{C(t)}{0,21}\right) *\left(-\frac{V}{R}\right)
$$

Thus, the results gained are presented in fig. 5 . 


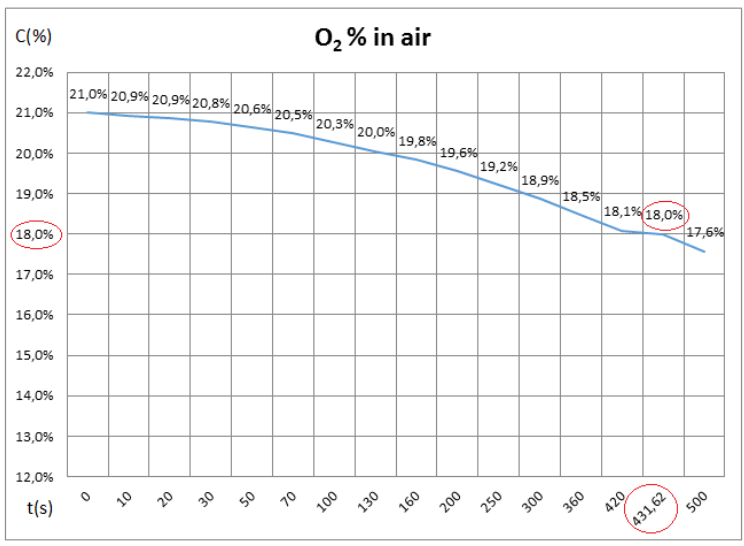

Figure 5: $\quad \mathrm{O}_{2}$ percentage in air decreasing in time.

Setting $C(t)$ at 0.18 , eqn (4) gives a time of $431.62 \mathrm{~s}$ that is the maximum time of stay in the building before reaching the critical conditions for people (the ASET parameter).

\section{Simulation hypothesis}

According to the work organization in the service building, the maximum crowding considered is of 11 people, divided as follows:

- ground floor (0f): n. 2 Italian male technicians;

- first floor $\left(1^{\text {st }} \mathrm{f}\right)$ : $\mathrm{n}$. 7 researchers of different nationalities, 3 of them women; - second floor $\left(2^{\text {nd }}\right.$ f): n. 2 male technicians of different nationalities.

N. 2 security guards and n. 2 firemen specialists ( 4 of the $624 \mathrm{~h}$-presence people in the Underground Laboratories as emergency team) ready to operate have been considered [8]. Table 4 refers to the parameters and hypothesis assumed for the agents and the scenario evolution considering the slow factor (a factor taking into account the athleticism of people and how quickly they reach a fatigue which reduces the speed of walking), weight, height, allowed movements.

\section{Results}

The respect of eqn (1) guarantees a safe and successful evacuation. The case study, and the performed simulation, emphasized the full respect of eqn (1). Specifically, the arrival time of the Guard 2 at the $2^{\text {nd }}$ floor of the Service Building, where the Technician4 was continuing his work not participating in the evacuation, has been calculated of 109.3 s. Moreover, the full evacuation of the building and the reaching of the safe place (South side filter) by all the $11+4$ people present took $178.53 \mathrm{~s}$. Thus, all the calculated times stand under the $431.62 \mathrm{~s}$. It can be observed that the number of agents reaching the South side filter in safe conditions after only $56.11 \mathrm{~s}$ is 11 (10 occupants of the Service Building and 1 security guard closing the queue). After $178.53 \mathrm{~s}$ also the two firemen, the security guard and the technician are "safe and sound" (fig. 7). 
Table 4: Parameters and hypothesis for the agents and the scenario evolution.

\begin{tabular}{|c|c|c|c|}
\hline Agent & Gender & Place & Description \\
\hline Technician 1 & $\mathrm{M}$ & Of & Italian, $1.80 \mathrm{~m}, 85 \mathrm{~kg}$, slow factor $0,1,45$ years old \\
\hline Technician 2 & $\mathrm{M}$ & Of & Italian, $1.70 \mathrm{~m}, 80 \mathrm{~kg}$, slow factor $0,1,40$ years old \\
\hline Researcher 1 & $\mathrm{~F}$ & $1^{\text {st }} \mathrm{f}$ & Italian, $1.65 \mathrm{~m}, 50 \mathrm{~kg}$, slow factor 2,30 years old \\
\hline Researcher 2 & $\mathrm{~F}$ & $1^{\text {st } f}$ & French, $1.60 \mathrm{~m}, 55 \mathrm{~kg}$, slow factor 2,35 years old \\
\hline Researcher 3 & $\mathrm{~F}$ & $1^{\text {stf }}$ & American, $1.50 \mathrm{~m}, 55 \mathrm{~kg}$, slow factor 2,45 years old \\
\hline Researcher 4 & $\mathrm{M}$ & $1^{\text {st }} f$ & Italian, $1.70 \mathrm{~m}, 80 \mathrm{~kg}$, slow factor $0,1,40$ years old \\
\hline Researcher 5 & $\mathrm{M}$ & $1^{\text {st } f}$ & French, $1.77 \mathrm{~m}, 76 \mathrm{~kg}$, slow factor $0,1,55$ years old \\
\hline Researcher 6 & $\mathrm{M}$ & $1^{\text {st }} \mathrm{f}$ & Italian, $1.70 \mathrm{~m}, 80 \mathrm{~kg}$, slow factor $0,1,40$ years old \\
\hline Researcher 7 & $\mathrm{M}$ & $1^{\text {st }} f$ & English, $1.78 \mathrm{~m}, 79 \mathrm{~kg}$, slow factor $0,1,43$ years old \\
\hline Technician 3 & $\mathrm{M}$ & $2^{\text {nd }} f$ & Italian, $1.70 \mathrm{~m}, 88 \mathrm{~kg}$, slow factor $0,1,39$ years old \\
\hline Technician 4 & M & $2^{\text {nd }} f$ & $\begin{array}{l}\text { Russian, } 1.82 \mathrm{~m}, 80 \mathrm{~kg} \text {, slow factor } 0,1,40 \text { years old. } \\
\text { Doesn't take part in evacuation because he could not hear (or } \\
\text { voluntarily ignored) the alarm }\end{array}$ \\
\hline \multicolumn{3}{|c|}{ Emergency team } & Behaviour \\
\hline Guard 1 & M & Hall B & $\begin{array}{l}\text { Closes the queue during evacuation and proceeds with the } \\
\text { evacuation of the Service Building towards the South side filter }\end{array}$ \\
\hline Fireman 1 & M & Hall B & $\begin{array}{l}\text { Wears the aqualung in less than } 50 \mathrm{~s} \text {, identifies the failure and } \\
\text { fixes it }\end{array}$ \\
\hline Fireman 2 & M & Hall B & $\begin{array}{l}\text { Wears the aqualung in less than } 50 \mathrm{~s} \text {, identifies the failure and } \\
\text { fixes it }\end{array}$ \\
\hline Guard 2 & M & Hall B & $\begin{array}{l}\text { Wears the aqualung in } 50 \mathrm{~s}+20 \mathrm{~s} \text { more than firemen, inspects } \\
\text { the Service Building ensuring the complete evacuation of it }\end{array}$ \\
\hline
\end{tabular}



(a)

(b)

Figure 6: The simulated environment: (a) south side of Hall B and (b) Service Building.

Fig. 8 highlights the flow rates (person/s) overcoming successfully specific "check points", namely the different exit doors, with the following legend:

- green: flux towards South side filter's door ("Door13"); between $80 \mathrm{~s}$ and $160 \mathrm{~s}$ there is no flux because the emergency team is still in Hall B;

- yellow: flux towards ground floor's door ("Door p0"); after $10 \mathrm{~s}$ the occupants in the ground floor are outside, then, the flux after $140 \mathrm{~s}$ is related to the firemen going away after solving the nitrogen release;

- blue: flux towards first floor's door ("Door 12"); at $100 \mathrm{~s}$ the flux is related to the passing of the security guard checking the floor; 
- violet: flux towards second floor's door ("Door p2"); after $120 \mathrm{~s}$ the flux is related to the escaping of the security guard and the technician unaware of the alarm.



Figure 7: Number of occupants in selected rooms.

\section{Flow Rates for Selected Doors}

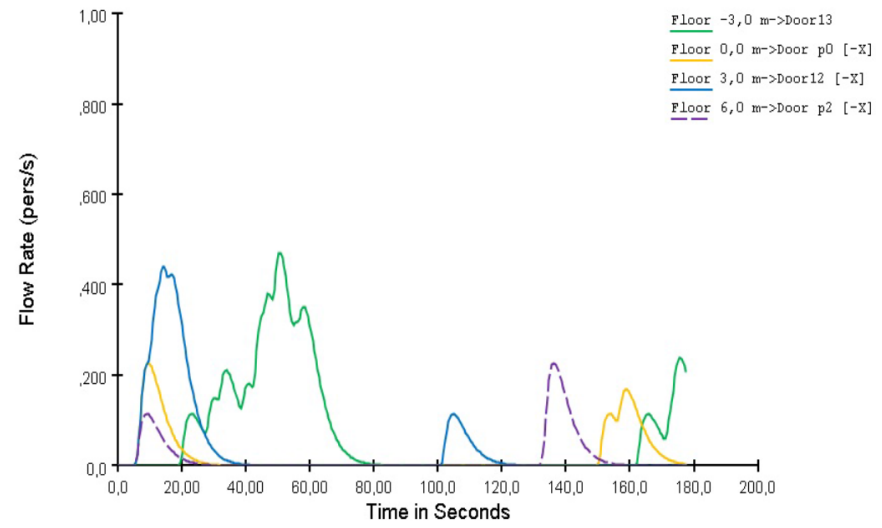

Figure 8: Flow rates for selected doors.

\section{Conclusions}

The goal of the study has been the critical analysis of a direct nitrogen release in the Service Building, in order to simulate and better study the response of users and LNGS' emergency team. The simulation carried out helped to evaluate the emergency procedures and their adequacy according to a performance-based approach founded on an agent-based model: FDS+Evac. The risk of asphyxia is a very crucial aspect in closed and confined spaces, such as the Underground Laboratories. The study, however, showed that the arrival time of the emergency 
team was adequate and lower than the time needed for an Oxygen Deficiency Hazard (ODH) atmosphere to occur. The results emphasized a right definition of the emergency procedures, integral part of the LNGS' Internal Emergency Plan (PEI).

The use of the presented interactive and dynamic tool testifies the utility of such approach, underlining, however, the need to validate the results with "real" emergency drills (to be performed periodically). Furthermore, the heterogeneous environment, with people coming from different countries and having diverse cultures, emphasize the need of these tests. Thus, aiming at avoiding situation of unheard/ignored alarms (such as the simulated one), it is out of doubt the importance of continuous training of LNGS' users and emergency teams in matter of safety and emergency procedures.

The potential of these tools is much higher if we consider the continuous improving on the modelling and characterization of human behaviour during an emergency from both a physical and psychological point of view.

The results obtained confirm the possibility to widen the analysis to the entire Underground Laboratories area, crosschecking the periodic emergency drills' results with the simulated emergency drills' ones. Finally yet importantly, the outcomes strengthen the opportunity to extend the study and the use of these tools in other INFN structures, in similar Underground Laboratories in the world and industrial plants with comparable risks.

\section{References}

[1] LNGS, Rapporto di sicurezza, 2011

[2] Arlington, Virginia: Compressed Gas Association, Oxygen Deficient Atmospheres (less than 19,5\%), CGA SB-2, 1992

[3] S. Marsella, L. Nassi, L'ingegneria della sicurezza antincendio e il processo prestazionale, EPC LIBRI, 2010

[4] NIST, Fire Dynamics Simulator (Version 5) - User's Guide, 2010

[5] NIST, Fire Dynamics Simulator (Version 5) - Technical Reference Guide, 2010

[6] VTT Technical Research Centre of Finland, Fire Dynamics Simulator with Evacuation: FDS+Evac Technical Reference and User's Guide, 2010

[7] FNAL, FESHM 5064: Oxygen Deficiency Hazards (ODH), Fermilab ES\&H Manual, 2012

[8] LNGS, Piano di Emergenza Interno rev. 04, 2013 